\title{
Les Cheminots dans l'histoire sociale de la France
}

Railwaymen in French social history

Pierre Vincent

\section{OpenEdition}

\section{Journals}

Édition électronique

URL : https://journals.openedition.org/rhcf/93

DOI : 10.4000/rhcf.93

Éditeur

Rails \& histoire

Édition imprimée

Date de publication : 1 décembre 2007

Pagination : 69-72

ISSN : 0996-9403

Référence électronique

Pierre Vincent, «Les Cheminots dans l'histoire sociale de la France », Revue d'histoire des chemins de fer [En ligne], 36-37 | 2007, mis en ligne le 10 mai 2011, consulté le 22 avril 2022. URL : http:// journals.openedition.org/rhcf/93; DOI : https://doi.org/10.4000/rhcf.93 


\title{
Les Cheminots dans I'histoire sociale de la France
}

\author{
Pierre Vincent \\ Ancien administrateur de la SNCF
}

Il s'agit d'un ouvrage à ambition historique commandité par la Fédération CGT des cheminots, dont la parution en 1967 doit coïncider avec le cinquantième anniversaire de la création de la Fédération (janvier 1917)*.

La décision a été prise au congrès de novembre 1965. Dès le départ, il a été décidé que l'ouvrage serait réalisé en interne par les propres moyens de la fédération, sans recours à un apport extérieur d'un historien mais avec l'ambition de réaliser un travail de nature historique.

À noter aussi que, dans la même période, il y a un mouvement d'écriture historique au sein de la CGT.

Par exemple, l'Esquisse de l'histoire de la CGT de Jean Bruhat et Marc Piolot ${ }^{1}$ est réactualisée et rééditée, Georges Frischmann, secrétaire général de la Fédération postale a entrepris d'écrire une histoire de sa Fédération; seul le premier tome qui s'arrête en 1946 paraitra $^{2}$. La Fédération du livre a confié à Paul Chauvet l'élaboration d'un ouvrage sur son histoire ${ }^{3}$.

Il y a donc un mouvement, qu'évoque Benoit Frachon dans sa préface ; à l'époque on évoquait l'ambition d'un ouvrage pour chaque branche professionnelle, il était aussi question d'une réappropriation de son histoire par la CGT. J'ai parfois une suspicion à l'encontre des historiens écrivant sur le sujet.

\footnotetext{
* Joseph Jacquet, et al., Les Cheminots dans l'histoire sociale de la France, Paris, Éditions sociales, 1967. Ce texte a été adressé par Pierre Vincent aux participants au séminaire avant la séance où il a témoigné sur l'écriture et la réception de l'ouvrage. [N.d.l.R., ainsi que toutes les notes qui suivent].

1- Jean Bruhat et Marc Piolot, Esquisse de l'histoire de la CGT, Paris, 1959, 238 p., réédité sous le titre complété Esquisse de l'histoire de la CGT (1895-1965), Paris, 1966, 383 p.

2- Georges Frischmann (1919-2006), secrétaire général de la Fédération postale CGT (1950-1979), député au Parlement européen (1979-1984), par ailleurs membre du comité central du parti communiste (1950-1979) puis du bureau politique (19541976). Son ouvrage est l'Histoire de la Fédération C.G.T. des P.T.T., des origines au statut des fonctionnaires, 1672-1946 (Paris, Éditions sociales, 1967, 582 p.).

3- Paul Chauvet, Les Ouvriers du Livre et du Journal. La Fédération française des travailleurs du livre, Paris, Éd. ouvrières, 1971, 346 p.
} 
Un point fort pour cet ouvrage, c'est que sa réalisation fut confiée à un militant de la direction fédérale particulièrement apte à ce genre de travail. Joseph Jacquet est un dirigeant qui a un profil inhabituel au sein de la fédération, il est d'origine chrétienne, ancien responsable de la Jeunesse ouvrière chrétienne (JOC). Son père était cheminot et était syndiqué à la CGT, il n'entra pas à la SNCF, travailla comme électricien et se syndiqua à la CFTC.

Né en 1921, la guerre sera une étape cruciale pour lui, il vécut dans la clandestinité. Et, au début 1943, à la suite d'une réunion d'anciens jocistes à Lyon, il fut décidé d'aller travailler en Allemagne pour influer sur les travailleurs allemands. Évidemment il sera vite repéré, condamné à mort pour sabotage puis déporté à Dachau d'où il sera libéré par les Américains en avril 1945. Il entre en avril 1945 à la SNCF et reprend des activités syndicales au sein de la CFTC. Il quitte cette organisation pendant les grèves de 1947, lui reprochant sa passivité dans l'action revendicative.

Il rejoint la CGT et occupera des responsabilités nationales dès 1956. Très attaché à la région lyonnaise, il refusera de la quitter et refusera de devenir permanent syndical, ce qui impliquait la montée à Paris.

Deux ans pour réaliser le travail. Objectif atteint. Ce fut vraiment un travail historique, avec recherches et examen des sources, de la bibliographie. Demande aussi faite aux syndicats d'envoyer leurs archives, ce qui marcha bien.

En résidence à Lyon, Joseph Jacquet demanda aux jeunes militants de la région de l'aider. Je fus un de ceux-là. En charge de la collecte sur la période du Front populaire, j’ai beaucoup lu, écrit de nombreuses notes, Joseph m'a demandé si je voulais rédiger cette partie mais j’ai refusé, estimant qu'il fallait une unité d'écriture.

Sur le contenu, nous en débattrons certainement. À l'époque il y a peu d'écrits sur les cheminots, Georges Ribeill n'était pas encore dans le circuit. Le livre de Guy Chaumel date de 19484. L'Histoire de la Fédération de Pierre Sémard a été écrite en 1934 et le prolongement écrit pendant sa détention est resté dactylographiés.

4- Guy Chaumel, Histoire des cheminots et de leurs syndicats, Paris, Marcel Rivière et Cie, Bibliothèque d'histoire économique et sociale, 1948, 199 p.

5- Voir la réédition de la brochure Histoire de la Fédération des cheminots dans Les Cahiers de l'Institut [CGT Cheminots], $\mathbf{n}^{\circ}$ 17, numéro spécial, $3^{\mathrm{e}}$ trimestre 2002, et le colloque «Pierre Sémard, 1887-1942. Histoire singulière d'un cheminot dirigeant syndical et politique, et figure héroïque » organisé par l'Institut et l'université de Bourgogne les 25 et 26 janvier 2007, actes parus sous le titre : Serge Wolikow (sous la dir. de), Pierre Semard, préface de Georges Séguy, Paris, Éditions Le Cherche-midi, coll. documents, 2007, 290 p.. 
Sur certains points, on peut penser que nous n'écririons pas les choses de la même manière. Le texte est parfois daté, avec certains jugements qui me paraissent trop définitifs avec beaucoup de noir et blanc. Près de quarante ans plus tard il y a des choses à revoir mais il n'est pas certain non plus que le texte ait perdu beaucoup de sa valeur.

Pour terminer, le problème majeur pour notre ouvrage, c'est qu'il a été achevé d'imprimer en décembre 1967 et que les événements de mai 1968 ont pour le moins atténué son actualité.

La CGT par la suite a connu un «certain sommeil » dans le travail historique qui reprendra vraiment avec la création des Instituts d'histoire sociale. Le confédéral est créé en 1982 après le départ de Georges Séguy du secrétariat général de la CGT ; il en prendra la présidence avec Joseph Jacquet comme vice-président. Ce dernier, après avoir été responsable régional de la CGT en Rhône-Alpes, avait créé un Institut régional d'histoire sociale.

Il avait aussi tenté de poursuivre un travail d'histoire avec une biographie de Pierre Sémard, mais, à l'époque, la non ouverture de certaines archives au niveau du parti communiste ne lui a pas permis de le faire.

Il est décédé le 18 février $1998^{6}$.

6- Joseph Jacquet était né en juillet 1921. Voir Maurice Moissonnier, «Jacquet Joseph, Marius ", in Marie-Louise Goergen (dir.), Cheminots et militants, un siècle de syndicalime ferroviaire, Paris, Les éditions de l'atelier, coll. Jean Maitron - Dictionnaire biographique du mouvement ouvrier français, 2003, p. 252-255. Les archives de la préparation du livre ont été léguées par J. Jacquet à l'Institut d'histoire sociale Rhône-Alpes de la CGT. 


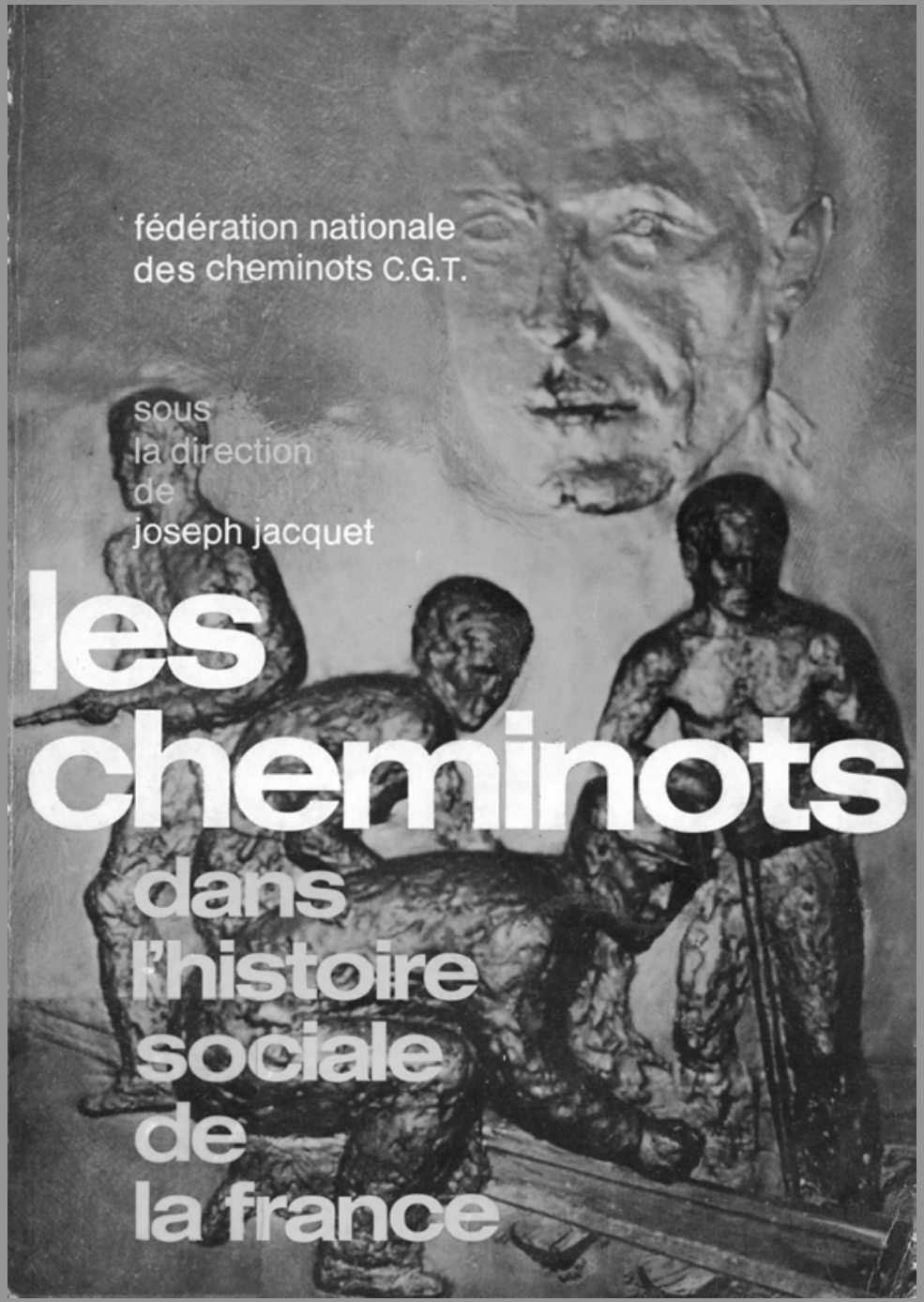

Couverture de l'ouvrage Les Cheminots dans I'histoire sociale de la France, sous la dir. de Joseph Jacquet, Paris, éd. sociales, 1967. 